\title{
The Impact of Students' Skills on the Use of Learning Support and Effects on Exam Performance in a Psychology Students' Statistics Course
}

\author{
Sarah Bebermeier \\ Bielefeld University
}

\author{
Fridtjof W. Nußbeck \\ Konstanz University
}

\author{
Kim L. Austerschmidt \\ Bielefeld University
}

\begin{abstract}
Support services to master academic requirements are offered at nearly every university. Thus, in the context of how students learn and how they achieve academic success, it is of great importance to investigate predictors of the use of support and the impact of support services on academic achievement. We present a longitudinal survey study with 3 cohorts of first-year psychology students. We investigated the relationship between subject-related mathematical skills and the use of 4 nonmandatory support services in a mandatory statistics course. Furthermore, we examined the role of skills and use of the support services in predicting academic success in statistics after the first year of study. We found that greater mathematical skills predicted less use of basic support services, $r \mathrm{~s}<-.150, \mathrm{ps}<.035$, and greater use of a skill-developing service, $r(195)=.199, p=.005$. Subsequently, we examined whether and how mathematical skills and service use predicted the grade in the final statistics exam. A mediation model revealed total effects for mathematical skills, tutorials led by advanced students, and a practice class $(\beta \mathrm{s}>.148, p \mathrm{~s}<.047)$, direct effects for mathematical skills and the tutorials $(\beta s>.306, p s<.001)$, and indirect effects via the self-reported competence in statistics for mathematical skills and online enrichment materials ( $a b s>.053, p \mathrm{~s}<$ .037). Finally, we discussed implications for lecturers.
\end{abstract}

Keywords: academic success, learning support services, psychology, mathematical skills

In the context of how students learn and how they achieve academic success, the transition from school to university, and the mastery of academic requirements at the very beginning of the studies, are highly relevant (Nelson, 2014):

Sarah Bebermeier, Department of Psychology, Bielefeld University; Fridtjof W. Nußbeck, Department of Psychology, Konstanz University; Kim L. Austerschmidt, Department of Psychology, Bielefeld University.

Correspondence concerning this article should be addressed to Sarah Bebermeier, Department of Psychology, Bielefeld University, P.O. Box 1001 31, D-33501 Bielefeld, Germany. E-mail: sarah.bebermeier@uni-bielefeld.de
Students must adapt to a new social environment (and disengage from the old one) and develop new learning strategies (Tinto, 2010; Trautwein \& Bosse, 2017). First-year university students are often overwhelmed by the stressors of the transition to university, which, in combination with difficulties meeting academic requirements, often results in a prolongation of, or even withdrawal from, the study program. These negative consequences concern many students, $30-50 \%$ of U.S. students withdraw from their studies or change their study major before graduation (O'Keeffe, 2013). Dropout or change rates in Germany fall in the range of 23-30\% (Destatis, 2009). In many disciplines (e.g., psychology, social or educational sci- 
ences, and economics), the high rates of withdrawal and change of subject may be due to the fact that first-year students are forced to pass statistics classes and research methodology courses at the beginning of their study programs while having negative attitudes or beliefs toward statistics (Doyle, 2017; Onwuegbuzie \& Wilson, 2003; Tremblay, Gardner, \& Heipel, 2000 ) and/or difficulties in courses with a mathematical focus (Dempster \& McCorry, 2009; Lalonde \& Gardner, 1993). In this regard, Chamberlain, Hillier, and Signoretta (2015) stated that support services are suitable for easing the learning of statistics.

Support services to master the critical phase of the first year are widely offered and usually belong to one of two categories: Some start before the beginning of the study program or even before enrollment into a specific subject to inform about, test, refresh, or deepen relevant subject-specific competences (Gass, 1987; Tierney, Bailey, Constantine, Finkelstein, \& Hurd, 2009). Others are offered parallel to the study program, and lecturers provide worksheets for self-paced individual practice, multimedia tools, or extra courses to repeat and deepen the content and to help students to develop their competences (Bebermeier \& Nussbeck, 2014; Neumann, Neumann, \& Hood, 2011; Wieling \& Hofman, 2010). It is common practice to let the students decide whether they deem the services helpful for their needs.

The present research refers to predictors of support service use in statistics and its effectiveness. An investigation of student characteristics, their relation to service use, and the benefit from the different services is highly relevant for lecturers to support students' learning and universities to support lecturers and students alike. Regarding the questions of if and how support services work, it is important to investigate the following:

(a) Who uses specific services (predictors of the use of [various] support services)?

(b) Effects of the services (consequences of the use of support services for academic achievement).

(c) Differential effects of various services (the interplay of students' characteristics, use of support services, and academic achievement).

\section{Support Services as Predictors of Academic Success}

Support before the beginning of the study can help students to decide on a subject and to recognize potential problems with the content of the study program and its requirements. Orientation programs can help undergraduates to adjust at university (Mayhew, Stipeck, \& Dorow, 2011), and preparatory courses lead to an improvement in task-specific confidence and competences (e.g., Carmichael \& Taylor, 2005; Schepmann \& Hughes, 2006).

Support during studies can help students to better understand course content, differentiate between more and less important topics, and get prepared for an exam. Peer mentoring programs (Rodger \& Tremblay, 2003) and self-regulated learning courses (Bail, Zhang, \& Tachiyama, 2008) can help students to achieve better grades. Also, blended learning environments can increase students' achievement. Video and audio podcasts can enhance the perceived control over learning, improve study habits, and increase performances (Williams, Birch, \& Hancock, 2012). In addition, the use of an online platform with videos, quizzes, and feedback affects students' course grades positively (Wieling et al., 2010).

Undoubtedly, support has to meet subjectspecific and individual needs, skills, and characteristics (Bebermeier et al., 2014; Winzker, Grein, Himmel, Kaul, \& Luppertz, 2014). As Rodgers, Posler, and Trible (2011) stated, some students overcome their deficits in a 3-week refresher course, whereas others require support for an entire semester.

Importantly, in the analysis of predictors of academic success different criteria for achievement should be taken into account: Usually, objective performance criteria, such as grades, serve as indicators of student success (Kappe \& Van der Flier, 2012; McKenzie \& Schweitzer, 2001). Recently, however, self-assessments of competences and success have been increasingly used as indicators for student learning and achievement (Boud, 2013; Topping, 2003). As Andrade and Valtcheva (2009) emphasized, self-assessments refer to strengths and weaknesses and, in addition to merely measuring performance, can promote learning and improve performances. 


\section{The Present Research}

In this study, we examined the effects of students' subject-related skills on the use of support services and effects of skills and service use on academic success longitudinally. We investigated students' skills in mathematics, use of various support services, and academic achievement over the first year of study.

We surveyed psychology students who attended an introductory statistics course and assessed their mathematical skills prior to the start of study and use of support services and selfreported competence in statistics at the end of the second semester. In addition, we assessed students' grade in the final statistics exam (after the second semester).

In total, four nonmandatory support services, tutorials led by advanced students, a practice class, worksheets for self-paced individual practice, and online enrichment materials, were provided. The tutorials and the practice class served to repeat and actively practice class content. In the tutorials, senior students taught firstyear students by repeating important concepts from the introductory statistics lectures and by running statistical analyses using the computer software R (R Core Team, 2016). Students in the practice class used a self-directed approach by working on statistical exercises either on their own or in small groups. In case students encountered difficulties, they could ask a senior student who was present during class hours. The self-paced individual practice also contained exercises, but students solved them without assistance at any convenient time and place and received stepwise solutions to evaluate their results. Finally, students used online enrichment materials to reflect upon the course content by indicating how well they understood the latest topics and by working on a small set (i.e., three to eight) of questions/exercises on these topics.

The aim of the tutorials led by advanced students, the practice class, and the self-paced individual practice is to teach basic subjectrelated skills. Students with low (mathematical) skills should benefit most. By contrast, the aim of the online enrichment materials is to extend subject-related skills through demanding and novel tasks. Accordingly, processing the questionnaires requires certain competences (e.g., verbalization of difficulties, reflection of solutions). Thus, this service addresses mainly stu- dents with moderate to high competences. We expected mathematical skills to predict the use of learning services in a way that students with lower (vs. higher) mathematical skills would be more likely to use the tutorials led by advanced students, the practice class, and the individual practice (vs. the online materials). We postulate:

Hypothesis $(H) 1$ : a significant, negative relation between mathematical skills and frequency of use of the tutorials and the practice class and the self-paced individual practice (H1a) as well as a significant positive relation between mathematical skills and frequency of use of the online enrichment materials ( $\mathrm{H} 1 \mathrm{~b})$.

Based on the literature, we expected mathematical skills to have a positive impact on academic achievement (i.e., high skills should lead to a greater self-reported competence in statistics at the end of the second semester and subsequently to better grades in the final statistics exam). We furthermore expected a significant relation between service use and academic success (i.e., regular use during the semester should lead to a greater self-reported competence in statistics after the second semester, and subsequently to better grades in statistics). We postulate:

H2: significant positive relations between mathematical skills and self-reported competence in statistics and the statistics grade (H2a), implying an indirect effect running from mathematical skills via self-reported competence to the statistics grade $(\mathrm{H} 2 \mathrm{~b})$ and significant positive relations between service use (tutorials led by advanced students, practice class, self-paced individual practice, and online enrichment materials) and self-reported competence and the statistics grade $(\mathrm{H} 2 \mathrm{c})$. More specifically, we hypothesized indirect effects running from service use via self-reported competence to the statistics grade (H2d) (see Figure 1).

\section{Method}

\section{Overview}

First-year psychology students of Bielefeld University (Germany), having started their studies over 3 consecutive years (2013-2015), were 


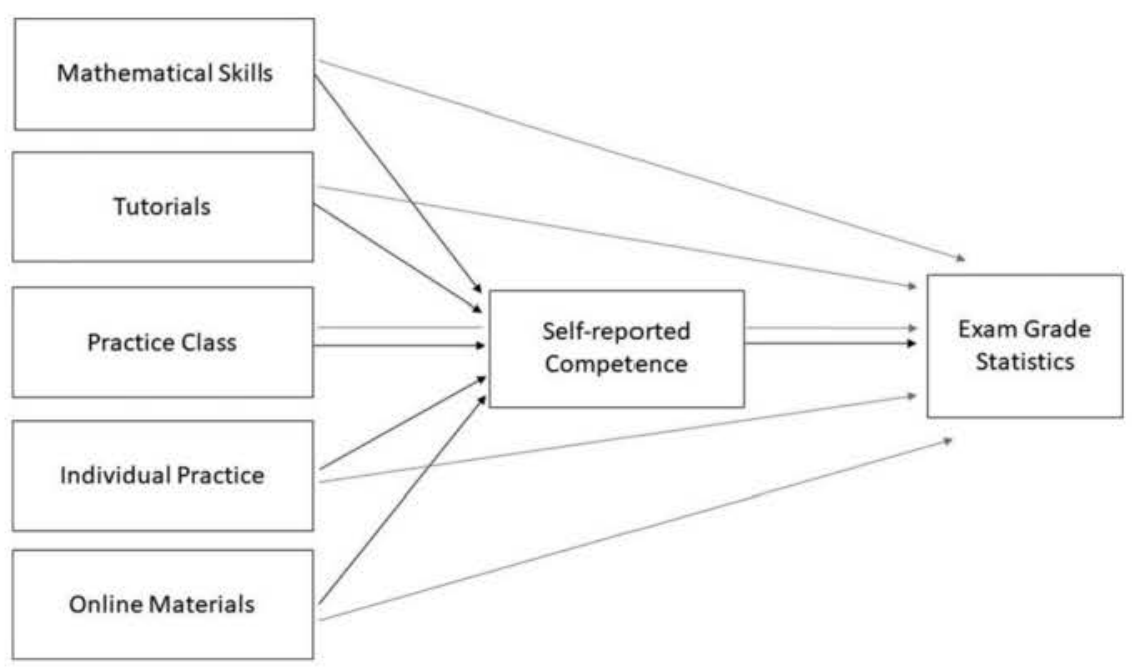

Figure 1. Proposed model for effects of mathematical skills and service use on competence and exam grade.

invited to participate in the study. During their first two semesters, all of them attended the introductory psychology statistics course. They filled in a first survey in the very first session of their first semester and a second survey in the last 2 weeks of the second semester, close to the final exam (taking place shortly after the second semester).

The first survey elicited students' sociodemographics and mathematical skills. The second assessed how often students had used the learning services (tutorials, practice class, individual practice, online materials) during their first and second semester and selfreported competence in statistics. Students created a personal code (in both surveys), enabling us to link together the answers of the surveys. We declared the purposes of the study (i.e., determine factors that influence student adjustment to university), informed students that participation was voluntary, and that all responses would be kept confidential and included a request for participation. We compensated participants with curricular credits.

\section{Participants}

Data from 482 respondents (of the three cohorts) exist. A total of 451 students answered the first, and 232 the second, survey. Among these, 250 participants responded only to the first survey and 31 only to the second one. Additionally, 277 students agreed to provide their grade on the statistics exam, with 172 students also having responded to both surveys, 85 only to the first one, and 20 only to the second one. Thus, 172 complete and 310 incomplete data sets exist.

We compared complete cases (completers) and incomplete cases (noncompleters) with respect to the study variables (see Supplemental Table A). Although we found statistical differences suggesting that completers meet the study requirements better, study in a more focused manner, use some support services more often, and perform better in the final exam, there are no differences in the estimated models testing the hypotheses separately for completers and noncompleters. Hence, we report the results for the total sample.

Furthermore, we compared respondents of the different cohorts (first: 166 respondents with 64 completers and 102 noncompleters, second: 150 respondents with 55 completers and 95 noncompleters, third: 166 respondents with 56 completers and 110 noncompleters; see Supplemental Table B). We found significant differences for mathematical skills, grade in statistics, and the use of support services. We did not find meaningful interaction effects of completeness and cohort. For all estimated models testing the hypotheses, we checked for differences between 
the cohorts. Results remain stable across the cohorts; hence, we present the results for the whole sample. However, we found a few specific differences in the results of the analyses (e.g., the direct effect of mathematical skills on the grade did not reach significance in the first cohort, a direct effect of online enrichment materials on the grade did occur in the first cohort), and the indirect effects of online materials on the grade via self-reported competence did not reach significance in the smaller cohort subsamples and thus decided to present the results of the indirect effects separately for each cohort in the Supplemental Material (see Supplemental Tables $\mathrm{Cl}-\mathrm{C} 3$ ). Table 1 shows gender and age of completers and noncompleters within the three cohorts.

Because female students were overrepresented in our sample, which corresponds to the ratio of male and female students in the population of psychology students (Sander \& Sanders, 2007), we analyzed for gender effects. We found gender differences for self-reported competence in statistics (women stated lower competences: $r(227)=-.156, p=.019)$ and use of the tutorials led by advanced students (women used the tutorials more often, $r(227)=.199$, $p=.002)$. For all other variables, we did not find differences ( $r$ s ranged from -.07 to .03 ). All associations between variables showing relevance for hypothesis testing were similar for women and men, although the effects mostly did not reach significance in the smaller subsample of men. However, because we did not expect women and men to differ in the associations of study variables and did not find differences in the absolute values of model parameters (model results), we report the results for the pooled sample.

\section{Measures}

\section{First Survey (at the Beginning of the First Semester)}

Mathematical skills. Twenty-one multiple-choice tasks assessed students' mathematical skills (four tasks in algebra, four in fractional arithmetic, four in percentage calculation, five in probability calculation, and four in the interpretation of graphics and tables; see Figure 2 for sample items).

\section{Second Survey (at the End of the Second Semester, Prior to the Final Exam)}

Support use. Participants indicated how frequently they had used the tutorials led by advanced students, the practice class, the selfpaced individual practice, and the online enrichment materials on four Likert-type items ( $1=$ never, 6 = always).

Competence in statistics. Participants rated their competence on the Likert-type item: "What do you think: How competent are you in methodology and statistics compared to your fellow students?"1 ( 1 = not at all competent, $6=$ very competent $)$.

Grade in statistics. During the final exam of the statistics module, scheduled after the second semester, students indicated their personal code on a voluntary basis. A person not involved in the research project and not having access to any data of the students linked the grade to the personal code, keeping all data anonymous to the research staff. Grades range from 1 (worst grade) to 5 (best grade).

\section{Results}

We used correlation analyses, linear regressions, and path analyses to test the hypotheses. Table 2 presents means, standard deviations, and zero-order correlations for all variables. Table 3 presents the distribution of service use.

We found the hypothesized relations between mathematical skills and use of supporting versus skill-developing services (H1): Mathematical skills are negatively related with the frequency of using the supporting services, tutorials, $r(196)=-.168, p=.018$, practice class, $r(196)=-.150, p=.035$, and individual practice, $r(195)=-.160, p=.025$, and positively related with the frequency of using the skill-developing online materials, $r(195)=$

\footnotetext{
${ }^{1}$ We asked for competence in statistics compared with fellow students, rather than competence in statistics in general, because psychology students in Germany are highly competent because of the central allocation of study places, depending on school grade point average. In general, psychology students are among the best $10 \%$ of pupils in their cohort according to their school grade point average. For academic achievement and especially the allocation of study places in the master's program, based on a social reference standard, a comparison with fellow students is more important.
} 
Table 1

Participants' Characteristics of Completers and Noncompleters

\begin{tabular}{|c|c|c|c|c|c|c|c|c|c|c|c|c|c|c|c|}
\hline \multirow[b]{4}{*}{ Variables } & \multicolumn{15}{|c|}{ Participants' characteristics } \\
\hline & \multicolumn{5}{|c|}{$\begin{array}{c}\text { Completers } \\
\text { (participated in S1 and S2) }\end{array}$} & \multicolumn{5}{|c|}{$\begin{array}{l}\text { Noncompleters } \\
\text { (participated in S1 only) }\end{array}$} & \multicolumn{5}{|c|}{$\begin{array}{l}\text { Noncompleters } \\
\text { (participated in S2 only) }\end{array}$} \\
\hline & \multicolumn{2}{|c|}{ Gender } & \multicolumn{3}{|c|}{ Age } & \multicolumn{2}{|c|}{ Gender } & \multicolumn{3}{|c|}{ Age } & \multicolumn{2}{|c|}{ Gender } & \multicolumn{3}{|c|}{ Age } \\
\hline & M & $\mathrm{F}$ & Md & Mean & $S D$ & M & $\mathrm{F}$ & $M d$ & Mean & $S D$ & M & $\mathrm{F}$ & Md & Mean & $S D$ \\
\hline $\mathrm{Cl}$ & 12 & 52 & 19 & 20.016 & 2.320 & 18 & 76 & 24 & 25.223 & 6.379 & 3 & 10 & 23 & 21.909 & 3.177 \\
\hline $\mathrm{C} 2$ & 8 & 47 & 20 & 20.800 & 3.535 & 19 & 72 & 22 & 23.336 & 5.352 & 1 & 8 & 21 & 22.444 & 3.712 \\
\hline C3 & 3 & 53 & 19 & 20.125 & 2.552 & 17 & 73 & 22 & 22.700 & 5.133 & 5 & 30 & 22 & 22.343 & 3.880 \\
\hline
\end{tabular}

Note. $\mathrm{S} 1=$ first survey; $\mathrm{S} 2=$ second survey; $\mathrm{C} 1$ to $\mathrm{C} 3=$ cohorts $1-3 ; \mathrm{M}=$ male; $\mathrm{F}=$ female; $M d=$ median.

$.199, p=.005$. Furthermore, we found the hypothesized relations between mathematical skills and academic achievement (H2a). Mathematical skills are positively related with selfreported competence, $r(196)=.326, p<.001$, and the statistics grade, $r(255)=.245, p<$ .001 . Also self-reported competence is correlated with the statistics grade, $r(188)=.545$, $p<.001$.

Likewise, in most cases, we found the predicted relations between service use and academic achievement (H2c): Frequency of use is positively related with self-reported competence (tutorials led by advanced students, $r(224)=.121, p=.069$, practice class, $r(224)=.161, p=.016$, self-paced individual practice, $r(221)=.164, p=.014$, online enrichment materials, $r(223)=.199, p=$ .003 ), and with the final statistics grade (tutorials, $r[188]=.322, p<.001$, practice class, $r[187]=.262, p<.001$, individual practice, $r[185]=.196, p=.007$, online materials, $r[186]=.270, p<.001)$.
Finally, we simultaneously specified all possible mediation effects running from mathematical skills, and the four services to self-reported competence, and ultimately, to the statistics grade in a path analysis with MPlus (Muthén \& Muthén, 1998-2017). In sum, $43.3 \%$ of the variance in the grade in statistics can be explained.

We found the presumed mediation for mathematical skills predicting the statistics grade (H2b). The total effect of mathematical skills on the grade is $\beta=.400(p<.001 ; 95 \%$ confidence interval $[\mathrm{CI}]=.290, .496$ ), with a direct effect (without mediation) $(\beta=.306, p<.001$; $95 \% \mathrm{CI}=.183, .414)$, and an indirect effect $(\beta=.094, p=.001 ; 95 \% \mathrm{CI}=.045, .160)$.

For effects of the services (H2d), we found a total effect of the tutorials led by advanced students on the grade, $\beta=.328(p<.001 ; 95 \%$ $\mathrm{CI}=.208, .436$ ), with a direct effect (without mediation) $(\beta=.319, p<.001 ; 95 \% \mathrm{CI}=$ $.204, .424)$ but no indirect effect $(\beta=.010, p=$ $.676 ; 95 \% \mathrm{CI}=-.035, .057)$. We further found
Algebra

$(-1)^{26+}(-3)^{2}+(-5)^{3}=$
$0-32$
$0-125$
$0-115$
$0-5$

$$
x^{6}+6 x^{4}=
$$$$
x^{2}\left(x^{2}+x^{4}+6\right)
$$$$
x^{4}\left(x^{2}+6\right)
$$$$
x^{2}\left(x^{4}+6 x^{4}\right)
$$$$
6 x^{2}\left(x^{2}-6 x^{4}\right)
$$

Fractional arithmetic

$$
\begin{gathered}
\frac{1}{3 a}-\frac{1}{2 a}+\frac{1}{a}= \\
\circ \frac{1}{2 a} \\
\circ \frac{5}{6 a} \\
\circ \frac{1}{6 a} \\
\circ \frac{5}{2 a}
\end{gathered}
$$$$
\frac{1}{4} \times \frac{1}{3} \times \frac{1}{6}: \frac{1}{20}
$$$$
\text { ㅇ } 1 \frac{7}{20}
$$$$
\text { ○ } \frac{1}{4}
$$$$
\text { ○ } \frac{3}{16}
$$$$
\text { ○ } \frac{5}{18}
$$

Figure 2. Examples from the measure of mathematic skills. 
Table 2

Zero-Order Correlations, Arithmetic Means, and Standard Deviations for All Observed Variables

\begin{tabular}{lccccccc}
\hline Variables & 1 & 2 & 3 & 4 & 5 & 6 & 7 \\
\hline 1. MS & - & & & & & & \\
2. CS & $.326^{* *}$ & - & & & & & \\
3. TS & $-.168^{*}$ & .121 & - & & & & \\
4. PC & $-.150^{*}$ & $.161^{*}$ & $.244^{* *}$ & - & & & \\
5. IP & $-.160^{*}$ & $.164^{*}$ & $.220^{* *}$ & $.448^{* *}$ & - & & \\
6. OM & $.199^{* *}$ & $.199^{* *}$ & $.198^{* *}$ & $.212^{* *}$ & $.200^{* *}$ & - & \\
7. GE & $.245^{* *}$ & $.545^{* *}$ & $.322^{* *}$ & $.262^{* *}$ & $.196^{* *}$ & $.270^{* *}$ & - \\
$M$ & 11.388 & 3.485 & 3.520 & 1.786 & 3.292 & 2.754 & 3.620 \\
SD & 4.029 & .985 & 1.674 & 1.374 & 1.827 & 1.744 & .981 \\
Range & $2-21$ & $1-6$ & $1-6$ & $1-6$ & $1-6$ & $1-6$ & $1-5$ \\
\hline
\end{tabular}

Note. $\quad$ MS $=$ mathematical skills; $\mathrm{CS}=$ self-reported competence in statistics; $\mathrm{TS}=$ tutorials led by advanced students; $\mathrm{PC}=$ practice class; IP = self-paced individual practice; $\mathrm{OM}=$ online enrichment materials; $\mathrm{GE}=$ grade in statistics exam.

${ }^{*} p<.05$. ${ }^{* *} p<.01$.

a total effect of the practice class on the grade, $\beta=.148(p=.047 ; 95 \% \mathrm{CI}=-.009, .282)$, with no direct $(\beta=.118, p=.110 ; 95 \% \mathrm{CI}=$ $-.037, .253)$ or indirect effect $(\beta=.030, p=$ $.230 ; 95 \% \mathrm{CI}-.012, .087)$. For the individual practice, we did not find a total $(\beta=.072, p=$ $.305 ; 95 \% \mathrm{CI}=-.066, .209)$, a direct $(\beta=$ $.033, p=.632 ; 95 \% \mathrm{CI}=-.100, .168)$, or an indirect effect $(\beta=.039, p=.155 ; 95 \% \mathrm{CI}=$ $-.010, .098)$ on the grade. And for the online enrichment materials, we did not find a total $(\beta=.087, p=.130 ; 95 \% \mathrm{CI}=-.029, .198)$ or a direct effect $(\beta=.034, p=.557 ; 95 \% \mathrm{CI}=$ $-.080, .149)$ but an indirect effect $(\beta=.053$, $p=.037 ; 95 \% \mathrm{CI}=-010, .111)$ on the grade.

Table 4 presents total, direct, and indirect effects (for results of the path analyses separately for each cohort, see Supplemental Tables $\mathrm{C} 1-\mathrm{C} 3$ ), and Figure 3 presents the standardized model results.

\section{Discussion}

We found that students' skills relate to the use of learning services: Students with previ- ously low mathematical skills used services more frequently in which they repeated the content of the lectures and learned basic competences (e.g., tutorials led by advanced students, practice class, and self-paced individual practice). Students with previously high skills more often chose the more challenging form of support and used that service more frequently in which they reflected and tested their knowledge and skills (online enrichment materials). These findings provide support for Hypotheses 1a and $1 \mathrm{~b}$ and confirm previous research (Bebermeier et al., 2014; Zervakis \& Mooraj, 2014): Students can assess their competences and needs accurately. They choose services in accordance with their individual skills and personal needs. Private conversations with students and open feedback in the surveys revealed that students regularly tried out each support service. At the beginning of the first semester, they participated in numerous services. After a while, they decided whether a specific support is helpful and then either continued participating or withdraw. We think that future research is necessary to

Table 3

Distribution of Service Use

\begin{tabular}{lcccccc}
\hline \multicolumn{1}{c}{ Variables } & Never & & & & \multicolumn{2}{c}{ Always } \\
\multicolumn{1}{c}{$n$} & $n$ & $n$ & $n$ & $n$ & $n$ & 19 \\
\hline Tutorials $(n=229)$ & 43 & 34 & 22 & 40 & 71 & 7 \\
Practice class $(n=229)$ & 150 & 38 & 9 & 11 & 14 & 37 \\
Individual practice $(n=226)$ & 54 & 42 & 25 & 31 & 37 & 24 \\
Online materials $(n=228)$ & 79 & 46 & 28 & 26 & 25 & 24 \\
\hline
\end{tabular}


Table 4

Path Analysis for Effects of MS, TS, PC, IP, OM, CS, and GE. (Bootstrap $N=$ 10.000)

\begin{tabular}{llllll}
\hline \multicolumn{1}{c}{ IV } & DV & $\beta$ & $S E(\beta)$ & $p$ & $95 \%$ CI \\
\hline Direct effects & & & & & \\
MS & GE & .303 & .058 & $<.001$ & {$[.183, .414]$} \\
CS & GE & .326 & .067 & $<.001$ & {$[.187, .449]$} \\
TS & GE & .319 & .056 & $<.001$ & {$[.204, .424]$} \\
PC & GE & .118 & .074 & .110 & {$[-.037, .253]$} \\
IP & GE & .033 & .069 & .632 & {$[-.100, .168]$} \\
OM & GE & .034 & .059 & .557 & {$[-.080, .149]$} \\
MS & CS & .289 & .064 & $<.001$ & {$[.157, .410]$} \\
TS & CS & .030 & .069 & .667 & {$[-.104, .167]$} \\
PC & CS & .091 & .070 & .195 & {$[-.047, .230]$} \\
IP & CS & .120 & .080 & .136 & {$[-.038, .276]$} \\
OM & CS & .162 & .066 & .015 & {$[.027, .286]$} \\
Indirect effects & & & & & \\
MS, CS & GE & .094 & .029 & .001 & {$[.045, .160]$} \\
TS, CS & GE & .010 & .023 & .676 & {$[-.035, .057]$} \\
PC, CS & GE & .030 & .025 & .230 & {$[-.012, .087]$} \\
IP, CS & GE & .039 & .027 & .155 & {$[-.010, .098]$} \\
OM, CS & GE & .053 & .025 & .037 & {$[.010, .111]$} \\
Total effects & & & & & \\
MS & GE & .400 & .052 & $<.001$ & {$[.290, .496]$} \\
TS & GE & .328 & .058 & $<.001$ & {$[.208, .436]$} \\
PC & GE & .148 & .074 & .047 & {$[-.009, .282]$} \\
IP & GE & .072 & .070 & .305 & {$[-.066, .209]$} \\
OM & GE & .087 & .058 & .130 & {$[-.029, .198]$} \\
\hline
\end{tabular}

Note. $\quad$ IV $=$ independent variable; $\mathrm{DV}=$ dependent variable; $\mathrm{MS}=$ mathematical skills; $\mathrm{GE}=$ grade in statistics exam; $\mathrm{CS}=$ self-reported competence in statistics; $\mathrm{TS}=$ tutorials led by advanced students; $\mathrm{PC}=$ practice class; $\mathrm{IP}=$ self-paced individual practice; $\mathrm{OM}=$ online enrichment materials.

examine the processes of proceeding or withdrawing participation as well as the relationship between needs within the study program (e.g., skill development) and/or private limitations (e.g., professional commitment, child care obligations) and the different uses and effects of support services.

Furthermore, we replicated gender differences regarding math-related self-efficacy and competence (Gwilliam \& Betz, 2001; Pajares, 2005) and participation in autonomous learning behaviors (Fennema \& Leder, 1990): Female students rated their competence lower than male students (even though their actual competence was the same) and more often used the guided support in the tutorials rather than the selfdirected support. When gender differences are salient and stereotypical threat is high, the performance and the achievement of women might be worse than the performance and the achievement of men (Spencer, Steele, \& Quinn, 1999;
Walton \& Spencer, 2009). We refer educators and universities to Spencer, Logel, and Davies (2016) for recommendations on how to reduce the pernicious effects of stereotype threat.

We further found that subject-related skills positively relate to the reported competence in statistics after the second semester and to the final grade in the statistics exam, providing support for Hypothesis 2a. Importantly, the effect of students' skills on academic success is mediated by their reported competence in statistics, providing support for Hypothesis $2 \mathrm{~b}$. Additionally, we found that a more frequent use of support services is linked to a higher perceived competence in statistics and to better grades as predicted in Hypothesis 2c. Hypothesis 2d was supported for online enrichment materials only, in which the observed effect of frequency of service use on the later statistics grade was mediated by the self-reported competence in statistics. This finding suggests, that the online 


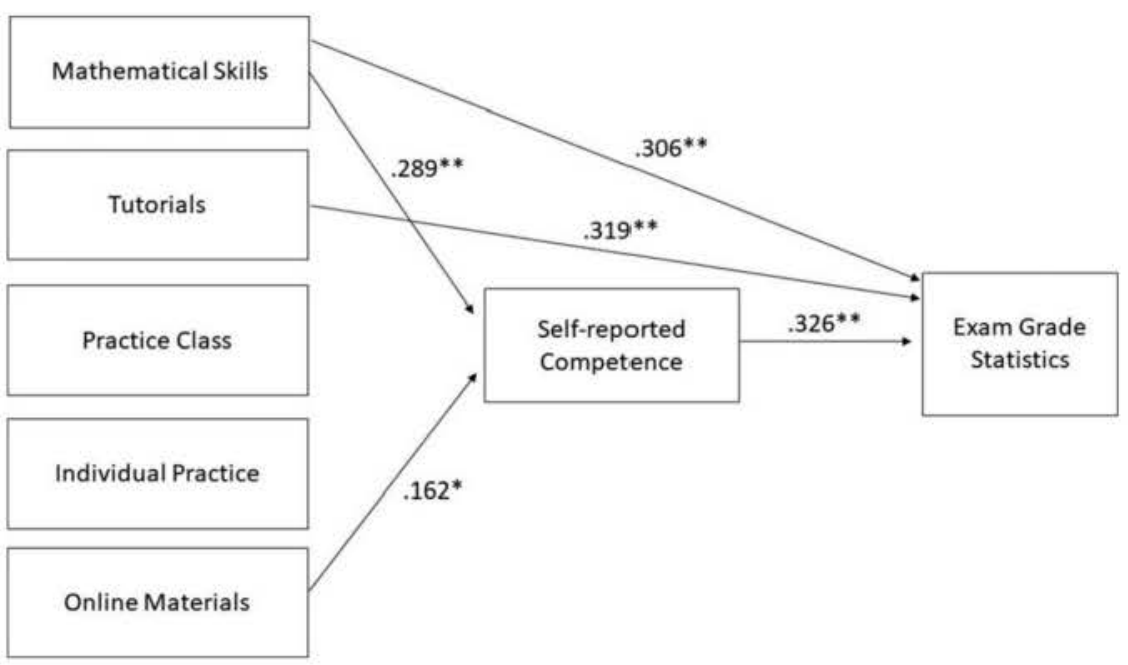

Figure 3. Standardized model results (only significant effects). ${ }^{*} p<.05 .{ }^{* *} p<.01$.

enrichment materials improve grades because the support enhances students' confidence and self-perceptions of competence but not because it improves exam-related skills. This is in line with previous findings indicating that self-assessments promote learning and engagement and, in turn, improve achievement (Andrade et al., 2009; Aydeniz \& Gilchrist, 2013). Yet it is also counterintuitive to the extent that the online enrichment materials were also supposed to solidify and extend statistics skills as well. Maybe the highly competent students who use this support benefit most from the process of reflection and less from the demanding tasks.

Additionally, we found total (but no indirect) effects on the later grade for the use of the tutorials led by advanced students and the practice class but no effects for the use of the selfpaced individual practice. This finding implies that the individual practice is not as effective at improving exam grades as support in a social context. Support with an advanced student (in the tutorials or the practice class) or peers (in the practice class) could also be understood as cooperative learning structures that have been shown to improve academic performance (Barrall \& Axelrod, 1978; Puzio \& Colby, 2013). Especially for the support with advanced students but also for the support with peers, one may also presume that students can more easily differentiate between more and less important topics because of the information exchange. Interestingly, practice and support in a social con- text do not enhance the self-reported competence in statistics. It may be that social practice enhances one's ability to assess one's competence in relation to peers more accurately but does not necessarily improve one's competence in comparison to peers.

In sum, these findings suggest that academic success substantially depends on skills students already have at study entry but also on their individual development and processes taking place during the first year of study. Although we did not measure change in self-reported competences, it is very likely that students become more confident in their competences because of their initially high competences and/or because of attending the services (see also the zero-order correlations in Table 2). We assume that students validate their assessments of their skills and knowledge relying on the requirements of the courses, the learning material and the provided tasks, on the available feedback, and/or on comparing themselves with their fellow students.

For academic success, we derive from these findings that it depends (at least to a certain extent) on the use of support services: The use of the (demanding) online enrichment materials is related to a higher perceived competence in statistics, and ultimately to better grades in statistics. The use of (less demanding) services (such as the tutorials or the practice class) relates to better grades in statistics, although this link cannot be explained by an increase in the 
perceived competence, at least not as measured in our survey: The item that was used ("How competent are you [. . .] compared with your fellow students") explicitly focuses on a comparison with other students. It is therefore conceivable that students who frequently use the less demanding services (such as the tutorials led by advanced students and the practice class) reduce their difficulties with the learning content and increase their competences, as well as the probability of achieving better grades, but do not perceive themselves as more competent than their fellow students. Hence, for the tutorials and the practice class, the self-reported competence, compared with fellow students, did not mediate the link between service use and academic achievement. We conclude that an exact distinction of competences that can be increased with learning services is essential for a deeper understanding of their impact besides that on the grade. Additionally, the item that was used to measure the frequency of service use ("How frequently have you used [...]"; 1 = never, $6=$ always) presumes that students make a meaningful and explicit distinction between the scale options. However, it is possible that options like always could convey different meanings to different students. Thus, future research should use (additional) measurements of competence, focusing on the personal improvement through service use as well as (additional) measurements of service use, focusing on absolute frequencies of services use. Furthermore, future research should examine differential effects of the use of different services for students with high versus low mathematical ability. It is of great interest whether high achievers benefit less from basic, merely supporting services, but more from skill-developing services, and whether the opposite is true for low achievers. Finally, future research should examine the generalizability of the findings to other populations of psychology students, who are not that selective as the highly competent psychology students in German universities as well as to students in other subjects.

Nevertheless, we can derive implications for lecturers and higher education institutions from our results: Because mathematical skills relate to a greater competence and better grades in statistics, as well as other modules (Steyer, Yousfi, \& Würfel, 2005), higher education institutions should emphasize the relevance of mathematical knowledge in the subject of psychology; for example, by the provision of precise and transparent information about the mathematical content on the one hand, and concrete and realistic requirements for applicants on the other hand. Furthermore, educators should provide support for students who meet the prerequisites sufficiently but not yet optimally: in the first place, before the study begins or at the very beginning, to detect and reduce deficits in mathematics as well as during the studies to help students to overcome their deficits and develop their skills further.

\section{References}

Andrade, H., \& Valtcheva, A. (2009). Promoting learning and achievement through self-assessment. Theory into Practice, 48, 12-19. http://dx.doi.org/ $10.1080 / 00405840802577544$

Aydeniz, M., \& Gilchrist, M. A. (2013). Using selfassessment to improve college students' engagement and performance in introductory genetics. Electronic Journal of Science and Mathematics Education, 7, 1-17.

Bail, F. T., Zhang, S., \& Tachiyama, G. T. (2008). Effects of a self-regulated learning course on the academic performance and graduation rate of college students in an academic support program. Journal of College Reading and Learning, 39. 54-73. http://dx.doi.org/10.1080/10790195.2008 .10850312

Barrall, M. E., \& Axelrod, S. (1978). The effects of teaming partners and retests on pretest-posttest scores, final course grades, and student attitudes. Research in Higher Education, 8, 177-187. http:// dx.doi.org/10.1007/BF00992118

Bebermeier, S., \& Nussbeck, F. W. (2014). Heterogenität der studienanfänger/innen und nutzung von unterstützungsmaßnahmen [Heterogeneity of firstyear students and the use of support services]. Zeitschrift für Hochschulentwicklung, 9, 83-100. http://dx.doi.org/10.3217/zfhe-9-05/05

Boud, D. (2013). Enhancing learning through selfassessment. London: Routledge. http://dx.doi.org/ 10.4324/9781315041520

Carmichael, C., \& Taylor, J. A. (2005). Analysis of student beliefs in a tertiary preparatory mathematics course. International Journal of Mathematical Education in Science and Technology, 36, 713719. http://dx.doi.org/10.1080/00207390500 271065

Chamberlain, J. M., Hillier, J., \& Signoretta, P. (2015). Counting better? An examination of the impact of quantitative method teaching on statistical anxiety and confidence. Active Learning in 
Higher Education, 16, 51-66. http://dx.doi.org/10 $1177 / 1469787414558983$

Dempster, M., \& McCorry, N. K. (2009). The role of previous experience and attitudes toward statistics in statistics assessment outcomes among undergraduate psychology students. Journal of Statistics Education: An International Journal on the Teaching and Learning of Statistics, 17, 1-7. http://dx .doi.org/10.1080/10691898.2009.11889515

Destatis. (2009). Erfolgsquoten 2008 [Success rates 2008]. Wiesbaden: Statistisches Bundesamt.

Doyle, D. A. (2017), Ugh . . . Statistics! College students' attitudes and perceptions toward statistics. Honors in the Major Theses. 165. Orlando, FL: University of Central Florida. Retrieved from https://stars.library.ucf.edu/honorstheses/165

Fennema, E., \& Leder, G. S. (1990). Mathematics and gender. New York: Teachers College Press.

Gass, M. A. (1987). The effects of a wilderness orientation program on college students. Journal of Experiential Education, 10, 30-33. http://dx.doi .org/10.1177/105382598701000208

Gwilliam, L. R., \& Betz, N. E. (2001). Validity of measures of math- and science-related selfefficacy for African Americans and European Americans. Journal of Career Assessment, 9, 261281. http://dx.doi.org/10.1177/1069072701009 00304

Kappe, R., \& Van der Flier, H. (2012). Predicting academic success in higher education: What's more important than being smart? European Journal of Psychology of Education, 27, 605-619. http://dx.doi.org/10.1007/s10212-011-0099-9

Lalonde, R. N., \& Gardner, R. C. (1993). Statistics as a second language? A model for predicting performance in psychology students. Canadian Journal of Behavioural Science, 25, 108-125. http://dx.doi .org/10.1037/h0078792

Mayhew, M., Stipeck, C., \& Dorow, A. (2011). The effects of orientation programming on learning outcomes related to academic and social adjustment with implications for transfers and students of color. Journal of the First-Year Experience \& Students in Transition, 23, 53-73.

McKenzie, K., \& Schweitzer, R. (2001). Who succeeds at university? Factors predicting academic performance in first year Australian university students. Higher Education Research \& Development, 20, 21-33. http://dx.doi.org/10.1080/ 07924360120043621

Muthén, L. K., \& Muthén, B. O. (1998-2017). Mplus user's guide (8th ed). Los Angeles, CA: Author.

Nelson, K. (2014). Keynote: The first year in higher education-Where to from here? International Journal of the First Year in Higher Education, 5, 1-20. http://dx.doi.org/10.5204/intjfyhe.v5i2.243

Neumann, D., Neumann, M., \& Hood, M. (2011). Evaluating computer-based simulations, multime- dia, and animations that help integrate blended learning with lectures in first year statistics. Australasian Journal of Educational Technology, 27, 274-289. http://dx.doi.org/10.14742/ajet.970

O'Keeffe, P. (2013). A sense of belonging: Improving student retention. College Student Journal, 47, 605-613.

Onwuegbuzie, A. J., \& Wilson, V. A. (2003). Statistics anxiety: Nature, etiology, antecedents, effects, and treatments-A comprehensive review of the literature. Teaching in Higher Education, 8, 195209. http://dx.doi.org/10.1080/13562510320000 52447

Pajares, F. (2005). Gender differences in mathematics self-efficacy beliefs. In A. Gallagher \& J. Kaufman (Eds.), Gender differences in mathematics: An integrative psychological approach (pp. 294 315). New York: Cambridge University Press.

Puzio, K., \& Colby, G. T. (2013). Cooperative learning and literacy: A meta-analytic review. Journal of Research on Educational Effectiveness, 6, 339360. http://dx.doi.org/10.1080/19345747.2013 .775683

R Core Team. (2016). R: A language and environment for statistical computing. Vienna, Austria: R Foundation for Statistical Computing (www.Rproject.org/).

Rodger, S., \& Tremblay, P. F. (2003). The effects of a peer mentoring program on academic success among first year university students. Canadian Journal of Higher Education, 33, 1-17.

Rodgers, K., Posler, B., \& Trible, L. (2011). A faster track: Decreasing the number of semesters students spend in developmental mathematics without lowering academic expectations. Problems, Resources, and Issues in Mathematics Undergraduate Studies PRIMUS, 21, 252-262. http://dx.doi .org/10.1080/10511970902995708

Sander, P., \& Sanders, L. (2007). Gender, psychology students, and higher education. Psychology Learning \& Teaching, 6, 33-36. http://dx.doi.org/ 10.2304/plat.2007.6.1.33

Schepmann, H. G., \& Hughes, L. A. (2006). Chemical research writing: A preparatory course for student capstone research. Journal of Chemical Education, 83, 1024. http://dx.doi.org/10.1021/ ed083p1024

Spencer, S, J., Logel, C,, \& Davies, P. G, (2016). Stereotype Threat. Annual Review of Psychology, 67, 415-437. http://dx.doi.org/10.1146/annurevpsych-073115-103235

Spencer, S. J., Steele, C. M., \& Quinn, D. M. (1999). Stereotype threat and women's math performance. Journal of Experimental Social Psychology, 35, 4-28. http://dx.doi.org/10.1006/jesp.1998.1373

Steyer, R., Yousfi, S., \& Würfel, K. (2005). Prädiktion von Studienerfolg: Der zusammenhang zwischen schul- und studiennoten im diplomstudien- 
gang psychologie [Prediction of study success: Relations between high school and college grades in psychology diploma studies]. Psychologische Rundschau, 56, 129-131. http://dx.doi.org/10 $.1026 / 0033-3042.56 .2 .129$

Tierney, W. G., Bailey, T., Constantine, J., Finkelstein, N., \& Hurd, N. F. (2009). Helping students navigate the path to college: What high schools can do: A practice guide (NCEE\#2009-4066). Washington, DC: National Center for Education Evaluation and Regional Assistance, Institute of Education Sciences, U. S. Department of Education. Retrieved from https://eric.ed.gov/?id=ED506465

Tinto, V. (2010). From theory to action: Exploring the institutional conditions for student retention. In J. C. Smart (Ed.), Higher education: Handbook of theory and research, 25 (pp. 51-89). New York: Springer. http://dx.doi.org/10.1007/978-90-4818598-6_2

Topping, K. (2003). Self and peer assessment in school and university: Reliability, validity and utility. In M. Segers, F. Dochy, \& E. Cascallar (Eds.), Optimizing new modes of assessment: In search of qualities and standards (pp. 55-87). Dordrecht: Kluwer Academic Publishers. http://dx.doi.org/10 .1007/0-306-48125-1_4

Trautwein, C., \& Bosse, E. (2017). The first year in higher education-Critical requirements from the student perspective. Higher Education, 73, 371387. http://dx.doi.org/10.1007/s10734-016-0098-5

Tremblay, P. F., Gardner, R. C., \& Heipel, G. (2000). A model of the relationships among measures of affect, aptitude, and performance in introductory statistics. Canadian Journal of Behavioural Science, 32, 40-48. http://dx.doi.org/10.1037/ h0087099
Walton, G. M., \& Spencer, S. J. (2009). Latent ability: Grades and test scores systematically underestimate the intellectual ability of negatively stereotyped students. Psychological Science, 20, 1132-1139. http://dx.doi.org/10.1111/j.1467-9280 .2009.02417.x

Wieling, M. B., \& Hofman, W. H. A. (2010). The impact of online video lecture recordings and automated feedback on student performance. Computers \& Education, 54, 992-998. http://dx.doi .org/10.1016/j.compedu.2009.10.002

Williams, A., Birch, E., \& Hancock, P. (2012). The impact of online lecture recordings on student performance. Australasian Journal of Educational Technology, 28, 199-213. http://dx.doi.org/10 14742/ajet.869

Winzker, M., Grein, M., Himmel, S., Kaul, M., \& Luppertz, C. (2014). Using evaluation data to initiate change in the study entry phase. Zeitschrift für Hochschulentwicklung, 9, 118-126. http://dx.doi .org/10.3217/zfhe-9-02/12

Zervakis, P., \& Mooraj, M. (2014). Der umgang mit studentischer heterogenität in studium und lehre. Chancen, herausforderungen, strategien und gelungene praxisansätze aus den hochschulen [Dealing with student heterogeneity in the study and in teaching. Opportunities, challenges, strategies and successful practical approaches from universities]. Zeitschrift für Inklusion, 2014, 1-2. http://www inklusion-online.net/index.php/inklusion-online/ article/view/222/224 